Gulawentah: Jurnal Studi Sosial

ISSN 2528-6293 (Print); ISSN 2528-6871 (Online)

Vol. 4, No. 1, Juli 2019, Hal 28-35

Tersedia Online: http://e-journal.unipma.ac.id/index.php/gulawentah

\title{
Pengembangan Sendang Bulus (Beji Pager) Menjadi Destinasi Wisata Baru di Kabupaten Ponorogo Serta Potensinya sebagai Sumber Belajar IPS Sekolah Dasar
}

\author{
Nurwati Rahayu \\ SDN 2 Bancangan Kecamatan Sambit,Kabupaten Ponorogo, Indonesia \\ Email: nurwatisrahayu@ gmail.com
}

\begin{abstract}
Abstrak
Penelitian ini bertujuan untuk menganalisis dan mendeskripsikan: (1) proses pengembangan Sendang Bulus (Beji Pager) sebagai destinasi wisata baru di Kabupaten Ponorogo, (2) potensi Sendang Bulus (Beji Pager) sebagai sumber belajar IPS Sekolah Dasar. Penelitian dilaksanakan mulai bulan April 2018 sampai dengan Maret 2019. Jenis penelitian ini adalah penelitian deskriptif dengan pendekatan kualitatif. Teknik pengumpulan data menggunakan metode wawancara, observasi, dan dokumentasi. Teknik keabsahan data menggunakan triangulasi teknik dan triangulasi sumber. Teknik analisa data melalui tiga tahap yaitu reduksi data, display data, kesimpulan/verifikasi.Dari penelitian yang dilakukan diperoleh hasil: (1) Pengembangan Sendang Bulus dilakukan melalui perbaikan akses jalan, budi daya ikan air tawar, penyempurnaan sarpras yang sudah ada, penambahan sarpras pendukung, pengelolaan oleh Kelompok Sadar Wisata (Pokdarwis) dan karang taruna di bawah naungan BUMDESA, dan kontribusi dari dinas pariwisata kabupaten. (2) Edukasi outdoor, fasilitas saling interaksi, pengamatan kongkrit, belajar berorientasi lingkungan, dan berpotensi untuk dapat digunakan sebagai sumber belajar IPS Sekolah Dasar Tema: Indahnya Negeriku, Kelas : 4 Semester 2, Kompetensi Dasar : Memahami manusia dalam dinamika interaksi dengan lingkungan alam, sosial, budaya, dan ekonomi.
\end{abstract}

Kata kunci: Destinasi Wisata; Sendang Bulus; Sumber Belajar IPS

\section{The Development of Sendang Bulus (Beji to be a Learningresource of Elementary School Social Science}

\begin{abstract}
This study aims to analyze and describe: (1) the development process of Sendang Bulus (Beji Pager) as a new tourist destination in Regency of Ponorogo, (2) the potency of Sendang Bulus (Beji Pager) as a resource of learning for elementary school social science. The research was conducted from April 2018 to March 2019.This study was descriptive research with a qualitative approach. The data were collected through interviews, observation, and documentation. The data retrieval technique was triangulation techniques and source triangulation. The data were analysed in 3 phases, they were data reduction, data display, and conclusion/verification.From the conducted research, the findings were obtained: (1) The development of Sendang Bulus was carried out through the improvement of the road access, cultivation of freshwater fish, improvement of existing facilities, addition of supporting facilities, management by Tourism Awareness Groups (Pokdarwis) and youth clubs under the BUMDESA, and the role of regency tourism office. (2) Outdoor education, mutual interaction facilities, concrete observation, and environmentally oriented learning were the potencies of Sendang Bulus as a learning resource of Social Science in Elementary School for the theme of Beautiful Country, Class: 4 Semester 2, Basic Competence: Understanding humans in the dynamics of interaction with the natural environment, social, culture and economy.
\end{abstract}

Keywords: Tourist Destination; Sendang Bulus; Social Science Learning Resource

DOI: 10.25273 /gulawentah.v4i1.4990

Copyright $\odot 2019$ Universitas PGRI Madiun

All rights reserved. 


\section{Pendahuluan}

Obyek dan daya tarik wisata adalah suatu bentukan dan fasilitas yang berhubungan yang dapat menarik minat wisatawan atau pengunjung untung datang ke suatu daerah atau tempat tertentu (Spillane, 1991). Pengembangan kepariwisataan saat ini tidak hanya untuk menambah devisa negara maupun pendapatan pemerintah daerah. Akan tetapi juga diharapkan dapat memperluas kesempatan berusaha disamping memberikan lapangan pekerjaan baru untuk mengurangi pengangguran. Pariwisata dapat menaikkan taraf hidup masyarakat yang tinggal di kawasan tujuan wisata tersebut melalui keuntungan secara ekonomi, dengan cara mengembangkan fasilitas yang mendukung dan menyediakan fasilitas rekreasi, wisatawan dan penduduk setempat saling diuntungkan. Pengembangan daerah wisata hendaknya memperlihatkan tingkatnya budaya, sejarah dan ekonomi dari tujuan wisata (Yoety, 2008).

Pengembangan pariwisata menurut (Arif, 2013) merupakan suatu rangkaian upaya untuk mewujudkan keterpaduan dalam penggunaan berbagai sumber daya pariwisata dan mengintegrasikan segala bentuk aspek di luar pariwisata yang berkaitan secara langsung maupun tidak langsung akan kelangsungan pengembangan pariwisata. Pengembangan pariwisata memberikan dampak positif dan keuntungan sebesar-besarnya baik bagi seluruh lapisan dan golongan masyarakat,pemerintah, swasta, maupun bagi wisatawan. Dampak positif yang diambil dari pengembangan pariwisata meliputi: 1) Penciptaan lapangan kerja, dimana pada umumnya pariwisata merupakan industri padat karya dimana tenaga kerja tidak dapat digantikan dengan modal atau peralatan; 2) Sebagai sumber devisa asing; 3) Pariwisata dan distribusi pembangunan spiritual, disini pariwisata secara wajar cenderung mendistribusikan pembangunan dari pusat industri ke arah wilayah desa yang belum berkembang, bahkan pariwisata disadari dapat menjadi dasar pembangunan regional. Beriringan dengan membuat daerah wisata baru penduduk sekitar juga disiapka agar mampu mengelola desa wisata, langkah yang dilakukan adalah dengan memberikan pelatihan kompetensi untuk mengelola desa wisata, sehingga pelestarian budaya dan pengentasan kemiskinan dapat terwujud (Susyanti \& Latianingsih, 2013). Menurut (Yoety, 2008) suatu daerah untuk menjadi daerah tujuan wisata (DTW) yang baik, harus mengembangkan tiga hal agar daerah tersebut menarik untuk dikunjungi, yakni: a) Adanya sesuatu yang dapat dilihat (something to see), maksudnya adanya sesuatu yang menarik untuk dilihat, dalam hal ini obyek wisata yang berbeda dengan tempat-tempat lain (mempunyai keunikan tersendiri). Disamping itu perlu juga mendapat perhatian terhadap atraksi wisata yang dapat dijadikan sebagi entertainment bila orang berkunjung nantinya. b) Adanya sesuatu yang dapat dibeli (something to buy), yaitu terdapat sesuatu yang menarik yang khas untuk dibeli dalam hal ini dijadikan cendramata untuk dibawa pulang ke tempat masing-masing sehingga di daerah tersebut harus ada fasilitas untuk dapat berbelanja yang menyediakan souvenir maupun kerajinan tangan lainnya dan harus didukung pula oleh fasilitas lainnya seperti money changer dan bank. c) Adanya sesuatu yang dapat dilakukan (something to do), yaitu suatu aktivitas yang dapat dilakukan di tempat itu yang bisa membuat orang yang berkunjung merasa betah di tempat tersebut.

Prinsip-prinsip pengembangan wisata alam dan kriteria-kriteria pengembangan dioperasionalisasikan dalam pengembangan pariwisata alam diarahkan pada: 1) Pengusahaan/pengembangan pariwisata alam dilaksanakan pada sebagian kecil areal blok pemanfataan, dan tetap memperhatikan pada aspek kelestarian; 2) Pengusahaan/pengembangan wisata alam tidak dibenarkan malakukan perubahan mendasar pada bentang alam dan keaslian habitat; 3) Pembangunan sarana dan prasarana pariwisata harus didasarkan pada identitas local; 4) Kegiatan pengembangan pariwisata harus melibatkan masyarakat setempat dalam rangka pemberdayaan ekonomi; 5) Pengembangan pariwisata harus mampu membuka lapangan kerja dan 
kesempatan usaha bagi masyarakat lokal. Pengembangan suatu daerah dapat disesuaikan oleh pemerintah daerah dengan potensi dan kekhasan daerah masing-masing (Prasetya \& Rani, 2014).

Konsep - konsep dasar IPS akan membawa kita secara aplikatif bagaimana membelajarkan IPS pada ranah praktis dan aplikatif. Karena mempelajari IPS berarti menghadirkan secara praktik sosial (social practice) materi kajian IPS untuk dapat diimplementasikan dalam kehidupan nyata (real of life)(Somantri, 2001; Suud, 2008).

Proses pendidikan di sekolah sejatinya adalah bagaimana mengantarkan peserta didik untuk menjadi warga negara yang baik serta dapat berinteraksi sosial dengan lingkungan sekitarnya. Secara teoritis pendidikan IPS membawa misi- misi tersebut untuk dapat mengantarkan peserta didik menjadi manusia seutuhnya yang memiliki kecerdasan sosial yang mumpuni (social smart) sesuai dengan jati diri karakter bangsa Indonesia (Somantri, 2001; Suud, 2008) menyatakan tujuan pendidikan IPS yang sesungguhnya adalah untuk mengembangkan pribadi peserta didik menjadi aktor sosial yang cerdas (intellegence social actor). Oleh sebab itu perlu dijelaskan terlebih dahulu konsep- konsep dasar IPS secara akademis lebih terperinci dan mendalam untuk tujuan pendidikan. Konsep - konsep dasar tersebut akan membawa kita secara aplikatif bagaimana membelajarkan IPS pada ranah praktis dan aplikatif. Karena mempelajari IPS berarti menghadirkan secara praktik sosial (social practice) materi kajian IPS untuk dapat diimplementasikan dalam kehidupan nyata (real of life).

Pembelajaran Pendidikan Ilmu Pengetahuan Sosial harus diarahkan pada upaya meningkatkan kualitas sumber daya manusia yang mampu melakukan "adaptation" dan "adjustment" dengan cepat melalui cara-cara yang cerdas, serta di dalam prosesnya mampu melibatkan pembuatan keputusan. Pendekatan yang diterapkan pada pembelajaran IPS, haruslah pendekatan multidimensional, atau ditinjau secara akademis harus interdisipliner atau multidisipliner. Dengan demikian upaya strategis untuk meningkatkan kemampuan berfikir ilmiah siswa dalam pembelajaran IPS akan segera terwujud. Kemampuan tersebut sangat dibutuhkan siswa dalam menghadapi kehidupan yang terus-menerus berubah dengan cepat. Pandangan siswa menjadi tetap realistik dengan memperhatikan local culture dan indigenous knowledge/ local wisdom karena pada akhirnya masyarakat itu sendiri yang akan memanfaatkan hasil dari pembelajaran tersebut. Oleh karena itu guru IPS di sekolah dasar dituntut memiliki kemampuan untuk dapat melakukan pendekatan interdisipliner atau multidisipliner dalam proses pembelajaran yang dilakukan. Meskipun saat ini mata pelajaran Ilmu Pengetahuan Sosial penyampaiannya diintegrasikan dengan mata pelajaran lain dalam suatu tema, namun tidak menghilangkan muatan materi yang harus dipelajari siswa dalam mata pelajaran IPS. Tujuan dari pengintegrasian mata pelajaran ini adalah agar pembelajaran menjadi lebih bermakna bagi siswa, sehingga penyusunan materi atau bahan ajar disesuaikan dengan lingkungan, karakteristik, dan kebutuhan peserta didik.

Berdasarkan kurikulum yang berlaku saat ini, bahan ajar yang digunakan masih bersifat nasional sehingga beberapa materi kurang sesuai dengan kondisi lingkungan belajar siswa. Umumnya bahan ajar yang digunakan dalam pembelajaran di SD menggunakan kurikulum 2013 adalah buku guru dan buku siswa. Hasil analisis dalam buku guru maupun buku siswa terbitan Kemendikbud Edisi Revisi 2018 kelas IV SD tema 6 Indahnya Negeriku Sub tema 2 Keindahan Alam Negeriku bahan ajar yang disajikan telah mencerminkan keunikan dari suatu daerah hanya saja belum didekatkan dengan lingkungan peserta didik dan masih bersifat nasional. Pengalaman yang diperoleh siswa akan semakin berkesan apabila proses pembelajaran yang diperolehnya merupakan hasil dari pemahaman dan penemuan siswa langsung. Dalam konteks ini siswa mengalami dan melakukan sendiri melalui proses pembelajaran yang berlangsung untuk merumuskan suatu konsep. 
Untuk memperoleh hasil belajar yang maksimal maka diperlukan sumber belajar yang didekatkan dengan lingkungan sekitar siswa.

Pengembangan sektor pariwisata juga bisa dimanfaatkan sebagai sumber pembelajaran dalam penyelenggaraan proses pendidikan. Ponorogo sebagai sebuah kabupaten berada di Provinsi Jawa Timur yang terkenal dengan sebutan Kota Reog memiliki destinasi wisata yang menarik. Beberapa destinasi wisata sudah dikenal dan menjadi favorit masyarakat luas, salah satu yang dikembangkan yaitu Sendang Bulus. Sendang Bulus di Desa Pager Kecamatan Bungkal Kabupaten Ponorogo sekarang menjadi destinasi wisata baru yang sangat menarik perhatian, banyak diminati pengunjung dan menjadi tempat studi wisata siswa- siswa Sekolah Dasar. Namun dari observasi awal guru belum memanfaatkan secara optimal sebagai sumber belajar, untuk itu perlu dilakukan penelitian.

\section{Metode Penelitian}

Penelitian ini menggunakan jenis penelitian deskriptif dengan pendekatan kualitatif. Sumber data pada penelitian ini adalah sumber data primer dan sumber data sekunder. Data didapat dari hasil wawancara dengan informan. Informan dari penelitian ini yaitu petugas yang mengelola Sendang Bulus Beji Pager, beberapa guru, wisatawan, perangkat desa, pemerintah daerah, sesepuh/tokoh masyarakat, serta masyarakat sekitar Sendang Bulus Beji Pager secara selektif. Sumber data sekunder yang digunakan dalam penelitian ini adalah profil Sendang Bulus Beji Pager, data yang diperoleh dari pengelola sendang berupa data tertulis, catatan orang lain, dokumen - dokumen grafis (monografi desa), laporan -laporan, foto- foto, rekaman video. Teknik pengumpulan data dengan wawancara, observasi, dan dokumentasi. Prosedur penelitiannya ada 3 tahap, yaitu (1) tahap persiapan (2) tahap pelaksanaan (3) tahap pelaporan. Teknik keabsahan data penelitian menggunakan triangulasi teknik dan triangulasi sumber. Analisis data menggunakan teknis analisis data model Miles dan Huberman yaitu analisis model interaktif.

\section{Hasil dan Pembahasan}

Setiap desa atau daerah pasti memiliki sejarah dan latar belakang tersendiri yang merupakan pencerminan dari karakter dan pencirian khas tertentu dari suatu daerah. Sejarah desa atau daerah sering tertuang dalam dongeng - dongeng yang diwariskan secara turun temurun dari mulut ke mulut sehingga sulit untuk dibuktikan secara fakta. Dalam hal ini Desa Pager juga memiliki cerita asal usul dan hal tersebut merupakan identitas dari Desa Pager yang merupakan hutan belantara yang lebat dan belum dijamah oleh manusia. Namun karena proses hidup dan kehidupan manusia serta perkembangan daya pikir manusia maka timbul persekutuan manusia yang hidup bersama pada suatu tempat tertentu yang hingga sekarang ini disebut desa.

Adapun sejarah timbulnya Desa Pager konon kabarnya menurut cerita dari para sesepuh Desa Pager adalah sebagai berikut, Raden Beku Prenggo Kusumo adalah Putra dari Demang Gading, Beliau Dua Bersaudara yaitu Raden Beku Prenggo Loyo dan Raden Beku Prenggo Kusumo. Kemudian Raden Beku Prenggo Kusumo karena desakan Belanda Beliau meninggalkan daerah Ngrayun turun ke arah utara dan sampailah di wilayah Hutan Gayam dengan pohon kayu Gayam yang besar - besar dan wingit / angker / gawat, lantas di babat dengan tujuan di jadikan sebuah Desa. Akhirnya Hutan Gayam yang dibabat tersebut dinamakan Desa Pager. Raden Beku Pringgo Kusumo mempunyai hewan kesayangan yaitu hewan Bulus dan Ikan Gabus (Kutuk) Raden Beku Pringgo Kusumo bersemedi di bagian sebelah timur agak ke utara dari asal babat desa, beliau minta kepada Tuhan Yang Maha Kuasa supaya diberi tempat untuk memelihara Bulus dan Ikan Gabus (Kutuk) 
akhirnya keinginanya terpenuhi, sehingga di tempat semedi tersebut keluar sumber mata air yang besar dan jernih yang akhirnya diberi nama Beji atau Sendang yang sampai sekarang di sebut sebagai (Sendang Bulus).

Desa Pager Kecamatan Bungkal dengan luas wilayah 460 Ha, terbagi menjadi 3 (tiga) Dukuh/Dusun/ Kamituwan yang merupakan satu wilayah di bawah pemerintah desa yaitu: 1) Bibis, 2) Glagah Malang, dan 3) Pager Tengah. Desa Pager memiliki 8 RW yang terdiri dari 16 RT. Batasbatas wilayah Desa Pager, sebelah utara: Desa Kupuk, sebelah timur: Desa Gajah Kecamatan Sambit, sebelah selatan : Desa Munggu, sebelah barat : Desa belang. Penduduk Desa Pager Kecamatan Bungkal mayoritas bermata pencaharian sebagai petani , dan mayoritas beragama Islam, jumlah penduduk berdasar data pemdes tahun 2018 sejumlah 1.880 orang dengan rincian laki-laki 944 orang dan perempuan 936 orang.

Latar belakang dalam menentukan pengembangan potensi unggulan daerah Sendang Bulus ini sudah ada semenjak menjadi tempat berkembang biak hewan langka Kura-kura (Bulus) yang sangat terkenal di kalangan masyarakat terdahulu.Sesuai pengamatan peneliti dan penjelasanpenjelasan informan dapat dimaknai bahwa perubahan pesat telah terjadi di Sendang Bulus (Beji Pager). Keasrian, rimbun pohon- pohon masih nampak namun sudah ada sentuhan di sana- sini yang tampil sebagai pemanis. Pada hari libur nasional dan hari libur sekolah Sendang Bulus (Beji Pager) semakin ramai pengunjung. Hari - hari biasa pun Sendang Bulus (Beji Pager) tidak pernah sepi dari pengunjung walau hanya sekedar menikmati kesejukan sendang dengan memancing atau sekedar duduk - duduk di pinggiran sendang. Potensi Sendang Bulus sebagai desa wisata harus digalakkan kembali. Diharapkan adanya perhatian dari Dinas Pariwisata untuk mengembangkan potensi Sendang Bulus (Beji Pager) sebagai destinasi wisata baru di Kabupaten Ponorogo. Melihat areal sendang cukup luas, Sendang Bulus (Beji Pager) lebih mudah untuk dikembangkan.

Nilai- nilai yang bisa diambil dari pengembangan Sendang Bulus (Beji Pager) diantaranya adalah nilai lingkungan alam, nilai sosial, nilai budaya, nilai ekonomi, bagaimana memahami manusia dalam dinamika interaksi dengan lingkungan alam, sosial, budaya,dan ekonomi. Sendang Bulus (Beji Pager) bisa menjadi tempat edukasi outdoor, siswa bisa berinteraksi dengan teman, dengan pengunjung lain, dan dengan makhluk dan benda yang ada di sekitar Sendang Bulus. Dengan berinteraksi dan pengamatan konkrit siswa dapat mengeksplor lingkungan sesuai dengan kreativitasnya. Berdasarkan hal- hal tersebut Pengembangan Sendang Bulus (Beji Pager) berpotensi untuk berkontribusi menjadi Sumber Belajar IPS Sekolah Dasar sesuai dengan Tema : Indahnya Negeriku, Kelas : 4, Kompetensi Dasar : a) Memahami manusia dalam dinamika interaksi dengan lingkungan alam, sosial, budaya, dan ekonomi; b) Menceritakan manusia dalam dinamika interaksi dengan lingkungan alam, sosial, budaya, dan ekonomi. Sumber daya alam, bagian dari sejarah yang merupakan kearifan local hendaknya dilestarikan (Suryawan, 2016).

Berdasarkan hasil penelitian dari pengembangan Sendang Bulus (Beji Pager) sebagai destinasi wisata baru di Kabupaten Ponorogo maka dapat disampaikan temuan penelitian sebagai berikut: 1) Sendang Bulus (Beji Pager) dikembangkan dengan perbaikan akses jalan menuju desa pager dengan mengadakan musrenbang 3 desa yaitu, desa pager, desa belang, dan desa bungkal mengusulkan perbaikan ke tingkat kabupaten. 2) Sendang Bulus (Beji Pager) dikembangkan untuk budidaya ikan air tawar. 3) Sarana prasarana Sendang Bulus (Beji Pager) yang sudah ada disempurnakan dan dikembangkan perencanaan gapura masuk, pagar keliling, arena outbond, taman agro edukasi, kolam renang, kolam bermain, wahana/sport selfie, wahana permainan, ruko, hall pertemuan, dan pengembangan pemukiman daerah wisata. 4) Pengembangan Sendang Bulus (Beji Pager) dikelola oleh Kelompok Sadar Wisata (Pokdarwis) dan karang taruna dibawah naungan BUMDESA. 5) Sumber dana pengembangan Sendang Bulus (Beji Pager) diperoleh dari alokasi dana 
desa, dari sponsor atau sumber dana lain, dan kontribusi kegiatan pelatihan souvenir dari dinas pariwisata kabupaten. 6) Peraturan tarif tiket masuk dan ongkos parkir serta sewa di Sendang Bulus (Beji Pager) masuk dalam Perdes (Peraturan Desa). Melibatkan warga sekitar dalam pengelolaan tempat wisata sangat bagus guna memperbaiki perekonomian masyarakat (Nugroho, Prihantanto, \& Pratikto, 2014).

Berdasarkan temuan penelitian 1, 2, 3, 4, 5, dan 6 di atas dapat dirumuskan proposisi, yaitu: Proposisi 1: Pengembangan Sendang Bulus (Beji Pager) dilakukan melalui perbaikan akses jalan menuju desa pager, budidaya ikan air tawar, penyempurnaan sarpras yang sudah ada, penambahan sarpras pendukung, pengelolaan oleh Kelompok Sadar Wisata (Pokdarwis) dan karang taruna dibawah naungan BUMDESA, sumber dana dari alokasi dana desa, dari sponsor/sumber dana lain, dan kontribusi kegiatan pelatihan dari dinas pariwisata kabupaten serta peraturan tarif tiket, ongkos sewa diatur dalam Perdes (Peraturan Desa). Pembelajaran Pendidikan Ilmu Pengetahuan Sosial harus diarahkan pada upaya meningkatkan kualitas sumber daya manusia yang mampu melakukan "adaptation" dan "adjustment" dengan cepat melalui cara-cara yang cerdas, serta di dalam prosesnya mampu melibatkan pembuatan keputusan. Pandangan siswa menjadi tetap realistik dengan memperhatikan local culture dan indigenous knowledge/ local wisdom karena pada akhirnya masyarakat itu sendiri yang akan memanfaatkan hasil dari pembelajaran tersebut.

Penjelasan para informan dapat dijadikan pijakan untuk mengatakan bahwa Sendang Bulus (Beji Pager) memiliki lokasi dan berbagai fasilitas yang berpotensi menjadi sumber belajar Siswa Sekolah Dasar. Berdasarkan hasil penelitian dapat disampaikan temuan- temuan penelitian sebagai berikut: 7) Sendang Bulus (Beji Pager) nyaman dimanfaatkan untuk kegiatan siswa- siswa SD bermain sambil belajar melalui wisata. 8) Sendang Bulus (Beji Pager) memiliki fasilitas cukup memadai seperti kolam renang, pemancingan, perahu bebek, outbond dan beberapa satwa lain yang dilindungi dipelihara di kebun binatang mini di Sendang Bulus Pager. 9) Sendang Bulus (Beji Pager) Sendang Bulus dapat dimanfaatkan untuk perkemahan atau edukasi outdoor. 10) Sendang Bulus (Beji Pager) memfasilitasi interaksi dengan sesama teman, pengunjung lain, makhluk dan bendabenda yang ada di sekitarnya. 11) Sendang Bulus (Beji Pager) memungkinkan proses pembelajaran lebih bermakna sebab dihadapkan pada pengamatan kongkrit. 12) Sendang Bulus (Beji Pager) sumber untuk belajar berorientasi pada lingkungan.

Mengembangkan bahan ajar yang berbasis kearifan local dapat meningkatkan rasa cinta terhadap lingkungan dan karakterk kebangsaan (Lestariningsih \& Suardiman, 2017). Berdasarkan temuan-temuan penelitian di atas maka dapat dirumuskan proposisi seperti di bawah ini: Proposisi 2: Bermain sambil belajar melalui wisata, fasilitas cukup memadai, edukasi outdoor, memfasilitasi interaksi dengan sesama teman, pengunjung lain, makhluk dan benda- benda yang ada di sekitarnya, pembelajaran dengan pengamatan kongkrit, dan belajar berorientasi lingkungan merupakan potensi Sendang Bulus (Beji Pager) sebagai sumber belajar IPS SD.

Pendekatan yang diterapkan pada pembelajaran IPS, haruslah pendekatan multidimensional. Pandangan siswa menjadi tetap realistik dengan memperhatikan local culture. Sendang Bulus (Beji Pager) adalah rekomendasi sumber belajar yang berorientasi pada lingkungan. Guru dapat memanfaatkan pembelajaran dengan mengeksplor lingkungan sesuai dengan kreativitas siswa, berfikir kritis, bergembira dan tentunya prinsip pembelajaran yang aktif, kreatif, inovatif, menyenangkan mudah diciptakan. Guru dapat memanfaatkan potensi Sendang Bulus (Beji Pager) sebagai sumber belajar melalui interaksi dan pengamatan konkrit. 


\section{Simpulan}

Pengembangan Sendang Bulus (Beji Pager) sebagai destinasi wisata baru di Kabupaten Ponorogo. Sendang Bulus erat kaitannya dengan Desa Pager. Akses jalan ke pariwisata Pager sudah bagus namun jalan di desa yang dilalui yaitu Desa Bungkal dan Desa Belang dalam kondisi rusak. Dari tiga desa yaitu Bungkal, Belang, dan Pager telah mengadakan musrenbang untuk mengusulkan perbaikan ke kabupaten. Sarana dan prasarana yang sudah ada adalah: Sendang bulus, Penangkaran Kura-kura (Bulus), Panggung/ Pendopo, 1 Gazebo, Wahana permainan sudah ada Perahu Bebek, Motor dan mobil Mini, Pemeliharaan Ikan air tawar (nila, tawes, gabus), Mushola, MCK. Rencana Pengembangan yaitu dengan penyempurnaan sarana dan prasarana meliputi: Gapuro masuk, Pagar Keliling, Arena Outbond, Taman Agro Edukasi, Kolam Renang dan Kolam bermain, wahana/ Sport Selfi, wahana permainan, ruko, hall pertemuan, dan pengembangan pemukiman daerah wisata. Pengelola pengembangan potensi desa wisata Sendang Bulus (Beji Pager) adalah Kelompok Sadar Wisata (Pokdarwis) desa pager dan karang taruna dibawah naungan BUMDESA Sendang Mulyo Desa pager Kecamatan Bungkal. Sumber dana untuk pengembangan Sendang Bulus (Beji Pager) diperoleh dari alokasi dana desa yang disesuaikan dengan kemapuan anggaran di desa, dari sponsor atau sumber dana lain. Kontribusi dari Dinas Pariwisata Kabupaten berupa kegiatan pelatihan pembuatan souvenir bagi masyarakat desa wisata. Tarif tiket masuk, ongkos parkir, ongkos sewa sarpras dan wahana permainan di Sendang Bulus (Beji Pager) masuk dalam Perdes (Peraturan Desa) dibahas bersama BPD dan masyarakat untuk diajukan di kabupaten

Sendang Bulus (Beji Pager) berpotensi untuk berkontribusi menjadi Sumber Belajar IPS Sekolah Dasar. Sendang Bulus (Beji Pager) nyaman dimanfaatkan untuk kegiatan siswa- siswa SD bermain sambil belajar melalui wisata, memiliki fasilitas cukup memadai seperti kolam renang, pemancingan, perahu bebek, outbond dan beberapa satwa lain yang dilindungi dipelihara di kebun binatang mini di Sendang Bulus Pager, dapat dimanfaatkan untuk perkemahan atau edukasi outdoor, memfasilitasi interaksi dengan sesama teman, pengunjung lain, makhluk dan benda- benda yang ada di sekitarnya. Sendang Bulus (Beji Pager) memungkinkan proses pembelajaran lebih bermakna sebab dihadapkan pada pengamatan kongkrit, dan merupakan sumber belajar berorientasi lingkungan. Pengembangan Sendang Bulus (Beji Pager) berpotensi untuk berkontribusi menjadi Sumber Belajar IPS Sekolah Dasar sesuai dengan Tema : Indahnya Negeriku, Kelas : 4, Kompetensi Dasar : a) Memahami manusia dalam dinamika interaksi dengan lingkungan alam, sosial, budaya, dan ekonomi; b) Menceritakan manusia dalam dinamika interaksi dengan lingkungan alam, sosial, budaya, dan ekonomi.

\section{Daftar Pustaka}

Arif, R. (2013). Pengembangan Pedagang di Obyek Wisata Sondokoro Kabupaten Karanganyar. Surakarta: Sebelas Maret University.

Lestariningsih, N., \& Suardiman, S. P. (2017). Pengembangan Bahan Ajar Tematik-Integratif Berbasis Kearifan Lokal Untuk Meningkatkan Karakter Peduli Dan Tanggung Jawab. Jurnal Pendidikan Karakter, 7(1). https://doi.org/10.21831/jpk.v7i1.15503

Nugroho, D., Prihantanto, A., \& Pratikto, I. (2014). Kabupaten Kendal Sebagai Objek Wisata Rekreasi Pantai. 3(November 2013), 332-341.

Prasetya, D., \& Rani, M. (2014). PENGEMBANGAN POTENSI PARIWISATA Kabupaten Sumenep, Madura, Jawa Timur (Studi Kasus: Pantai Lombang). Jurnal Politik Muda, 3(3), 412-421.

Somantri, N. . (2001). Menggagas Pembaharuan Pendidikan IPS. Bandung: Remaja Rosda Karya. 
Spillane, J. J. (1991). Ekonomi pariwisata : sejarah dan prosepeknya (Cet. 5.). Deresan Yogyakarta: Kanisius.

Suryawan. (2016). Peran Kelompok Sadar Wisata (Pokdarwis) Sendang Arum dalam Pengembangan Potensi Pariwisata (Studi Kasus Di Desa Wisata Tlahap Kecamatan Kledung Kabupaten Temanggung). Jurnal Elektronik Mahasiswa PLS, 5(6), 143-152.

Susyanti, D. W., \& Latianingsih, N. (2013). Potensi Desa melalui Pariwisata Pedesaan. Ekonomi Dan Bisnis, 12(1), 33-36. https://doi.org/10.1152/ajpheart.00083.2011

Suud, A. (2008). Revitalisasi Pendidikan IPS. Semarang: Unnes Press.

Yoety, O. A. (2008). Ekonomi pariwisata : introduksi, informasi, dan aplikasi. Jakarta: Penerbit Buku Kompas. 